\title{
Characteristic Resources Construction and Service Countermeasures of Famous University Libraries in Taiwan
}

\author{
Jing Zhang
}

Library of Beijing Normal University, Zuhai, Zhuhai, China

\begin{abstract}
Key words: Taiwan, University Library, Characteristic resources, Characteristic collection
Abstract: The construction of characteristic resources is one of the key construction of University Libraries in Taiwan, study the current situation and characteristics of University Library on the mainland, can tube reference to the construction of characteristic resources, the Mainland University Library in the construction of characteristic resources, according to the geographical and cultural environment to further strengthen self construction, enrich the collection.
\end{abstract}

\section{台湾知名高校图书馆特色资源建设及服务对策}

\author{
张晶 \\ 北京师范大学珠海分校图书馆，珠海广东 519085
}

关键词: 台湾; 高校图书馆; 特色资源; 特色馆藏

中文摘要：特色资源建设是台湾高校图书馆建设的重点之一, 研究其现状与特点, 可以对内 地的高校图书管特色资源建设起到借鉴作用，内地高校图书馆在特色资源的建设上，需要根 据地域与人文环境来进一步加强, 更加丰富自身的馆藏建设。

\section{1 引言}

特色资源建设是高校图书馆持续发展的重要基础，也是高校文献资源建设的重要组成部 分。随着电子化进程的日益发展, 高校图书馆的馆藏也逐渐进行了重心的转移, 纸质藏书与 电子资源的比例也在发生变化, 各高校在建设文献资源的过程中, 更加侧重适合自己学校及 学科的资源篮选, 建设有自身特色的馆藏资源。台湾高校的特色资源建设相对来说更有自身 的特色, 针对海峡两岸的共性与差异进行研究。选取台湾的高校作为研究对象, 主要是两岸 同源, 经验比较适合我们内地高校的特色资源建设发展。本文根据 2015 年全球大学排名资料 库, 选取台湾 10 所著名高校, 通过访问高校的图书馆网页, 获取特色资源建设的相关资料。 这 10 所高校包括国立台湾大学、国立中央大学、国立交通大学、国立成功大学、国立清华大 学、国立政治大学、国立中山大学、国立淡江大学、国立台湾师范大学、国立中正大学 (以下 省略 “国立”）。

\section{2 台湾高校高校特色资源建设现状}

\section{1 特色资源种类}

在研究台湾这几所高校图书馆的特色馆藏中，发现特色馆藏的方式都集中在这几类:

(1) “特色馆藏”, 主要有台湾大学、中山大学、台湾师范大学等;

(2) “校史与特藏”, 主要有清华大学;

（3）“机构典藏”，机构典藏（institutional repository）是开放获取运动中的一个重 要内容, 是由机构提供一个平台, 由机构成员自己将个人或机构的研究成果提交到机构典藏 库中, 在一定范围内传播使用, 并进行长期保存。主要有中央大学、交通大学、成功大学、 
淡江大学、中正大学、台湾师范大学等几所高校;

(4) “数位典藏” 或者 “数位化资源”，数位典藏（digital archive）指的是以数位方 式处理 (拍摄、全文输入、扫描等), 并加上元数据 (Metadata) 的描述, 以数位档案的形式储 存。开展数位典藏的图书馆主要有台湾大学、交通大学、中央大学、政治大学、中正大学、 台湾师范大学。其中中央大学的昆曲数位典藏非常有特色, 中央大学成立的戏曲研究室, 进 行戏曲文献、文物的搜集整理, 以昆曲和台湾本土戏曲、音乐为主, 是中央大学的一大特色。

\section{2 特色资源类型}

台湾高校特色资源的类型比较多样化，主要包括珍善本图书、古籍、私人珍藏（书信、 手稿、剪报、日记、照片)、地方统计及研究资料、戏曲典藏、唱片、手稿、校史资料、教工 科研成果。

台湾大学的特色馆藏就主要包括台湾地区的史料，包括台湾、日本、东南亚、亚洲各地 的资料，还有中文善本与线装书、日本汉典、历代案例、西文善本、名家手稿等资源，是台 湾地区保存相对完整的极具特色的馆藏资源; 台湾师范大学收集保存了亚洲著名学者 Gernot Prunner 私人图书馆的大量稀有藏书, 是研究亚洲的重要资源, 黑胶唱片是灵也特别的典藏, 收录了 1920 至 1950 年代台湾传统戏曲音乐最受欢迎的唱片代表作; 中央大学成立了戏剧研 究室, 主要进行昆曲文物、文献和影音资料的收集研究; 清华大学特色典藏主要包含台湾文 化结名人的手稿、文书, 以及战后的文物及史料, 其中最为著名的就是(1)台湾文化界叶荣钟 先生的手稿、文书以及生前收藏之日至战后 70 年代的史料文物（2003)，(2)林孝信先生收藏 的保钓运动及相关活动值刊物、手稿、文献等资料 (2004), (3)杨儒宝与方圣平先生收藏多年 的日治时期日人与台人书画数位典藏（2008）与实体文物（2014）, (4)抗战时期中国东北地下 抗日运动, 其以后《滚滚辽河》闻名的纪纲(本名赵岳山)先生创作的手稿、史料（2009), (5) 参与保钓运动、积极投入乡土改革的唐文标先生手稿文献（2010）等。

\section{3 特色资源数字化}

台湾高校图书馆为了提高特色资源的文献利用率, 对一些善本与孤本进行了数字化处理。 台湾大学图书馆建立全文影像资料库，包括淡新档案、台湾古碑拓本、伊能嘉矩手稿、田代 安定手稿狄宝塞文库等; 中央大学将昆曲戏曲研究室的成果进行数位化, 通过网络培养观众 与学术研究人才, 使台湾成为昆曲演出和学术研究的重镇, 并间接提升其他戏曲的演出水平; 台湾师范大学将古籍数位化, 其中全文影像共 1000 多册; 清华大学的数位校史馆, 将清华的 重要校史资料与互动知识库系统结合, 用多媒体模式加以呈现; 中山大学专门成立了余光中 数位文学馆, 主要包括余先生的诗集、散文、评论、书序、翻译、照片、讲座、报道等数位 化资料

\section{4 特色资源服务模式}

台湾高校的特色资源服务模式主要有闭架调阅、馆藏展览、社会推广、多媒体影展、网 络检索、资料出版、线上论题等服务模式。

台湾师范大学的善本古籍采取闭架管理, 每次限借一种, 由专人陪同阅览, 要复印, 也 需专人陪同, 限印本书十页以内; 台湾大学在对特藏资料的保藏中, 对有些善本数目进行了 出版, 还对闭架书库的珍藏善本以仿真品的形式进行展示, 对于名家手稿也会举办手稿展览 或出版相关书籍; 清华大学对私人名家的手稿会举行手稿展览, 对其典藏书籍进行闭架管理, 不提供外借, 如需调阅须填写调阅申请书, 于预订使用前一周申请并获核准后方能使用; 中 山大学的余光中数位资料馆开设了线上论坛, 登记为会员便可进行讨论、发表观点; 政治大 学图书馆提供免费的网络全文数位资源, 支援系统间的互通性, 并能够提供多种搜索引擎与 其他检索工具进行查询; 成功大学会定期在图书馆举办各种特藏资源的展览活动, 并通过多 媒体影展等方式推广本馆的特色馆藏。

\section{5 特色资源的共性特点}

研究台湾高校图书馆的特色资源建设, 发现各个高校在针对特色资源的建设过程中, 都 会相当重视中国传统文化的保留与传承, 这点笔者印象尤其深刻, 各个高校在继承与保留传 
统文化的过程中，会针对各自的学校特点，选取有益于自身学科发展的资源进行特藏，既有 共性又有特性, 史料丰富, 对各个朝代的古籍善本都有收藏, 并且精心维护, 比如台湾师范 大学的善本古籍, 会采取恒温设备, 定期进行熏蒸、除虫作业, 以便有效保管。

\section{3 对内地高校图书馆特色资源建设的启示}

\section{1 特色资源建设}

（1）按学科特色建设。在特色资源的建设中，各个高校的学科设置都不一样，所以在收 藏的过程中, 应该首先要了解高校自身的学科设置, 学科的科研情况, 根据馆藏设置, 合理 分配经费, 对于重点学科、骨干专业, 可以有针对性的进行资料的收集、采购, 重点收藏、 重点建设, 以保证学科资源的系统性、完整性。

（2）按学校属性建设。参考台湾高校的做法，学校的特色资源建设主要就是教职工以及 学生的科研成果的收藏, 主要包括师生撰写的著作、论文、手稿、专利发明、研究生的学位 论文, 尤其是发表在高质量的国际性学术期刊上的论文; 参加的高质量的国际学术型会议及 会议论文; 外部专家教授的演讲稿; 具有纪念意义的校史活动以及学校规划, 图书馆都用重 点收集、重点建设, 成为本校独具特色的馆藏资源。

（3）按主题与属性建设。所谓的主题与属性，就是按照某种鲜明的主题或者属性进行集 中抽取, 来形成自身的特色资源库, 台湾的高校根据自身学科的设置, 会集中选出重点, 进 行收藏

\section{2 特色资源管理}

(1)特色资源的宣传, 首先需要加强图书馆网站的建设, 使读者获取资源更加便捷快速, 特色馆藏的页面可以单独列出; 其次加强馆内的展览及海报, 经常举办特色资源某个命题的 讲座，提高特色资源的普及。

（2）特色资源的服务，在对特色资源的服务过程中，高校图书馆应该对咨询、辅助课程 的教学重视起来，由参考咨询的专业馆员进行特色资源的解答，保证质量。

(3) 特色资源数字化，根据台湾高校图书馆的做法，几乎将有价值、难保存的特色文献 都进行了数字化管理, 这样极大的提高了文献的利用率, 我们也可以学习将特色文献进行原 版数字化, 以便保存原貌, 方便阅读, 也可以利用网上图书馆进行补充、完善自己的特色馆 藏。

\section{4 结语}

台湾高校的特色资源建设与服务的发展都比较成熟，为我们提供了很好的学习与借鉴经 验。只要我们根据自身图书馆的发展规划, 扬长避短, 高校特色资源的建设一定会有更蓬勃 的发展。

\section{References}

[1] Wang Jingjing. Evolving academic environment and new direction of library resource construction [J]. University Library Journal.2015(4)

[2] Kim Yiming. characteristics of Library Resource Construction[J] .Journal of University Libraries.2008,26(6)

[3] Hou Aihua. Characteristic collection construction and service analysis of American famous university libraries [J]. Library Science Research.2014(22)

[4] Zhu Weiqiao. Thinking on the construction of characteristic collection oriented by key disciplines [J]. Library Journal.2013(11)

[5] Chen Xiaohui. Characteristics and analysis of regional research literature resources construction [J]. Library work and research.2008(9) 